\title{
16 Reading instruction and support
}

\author{
Pamela Snow, Kate de Bruin, and Linda Graham
}

\section{How to use this policy}

Strong reading skills are critical for academic success. Exposure to effective reading instruction is important for students of all ages but particularly critical for those in the first three years of school in order to prevent gaps in student achievement and progress. This policy highlights the key components of reading that should be taught, as well as the instructional approaches that research shows are most effective. Also outlined are recommendations that research suggests are key to providing timely and equitable interventions on the basis of need. This policy example is intentionally broad and authors of school policy are encouraged to refine and adapt the suggestions below to create a policy that best reflects the needs and context of their school.

\section{[INSERT name of school] Reading instruction and intervention}

\section{Rationale}

Strong reading skills ${ }^{1}$ are critical for academic success at all levels of schooling. To ensure that all students achieve reading competency, instructional time must be used judiciously to maximise exposure to explicit, systematic, and evidencebased instruction. This is important because research shows that this instructional approach optimises students' engagement with the curriculum and reduces the likelihood of them falling behind. Maximal exposure is particularly critical in the first three years of school; however, continued effective teaching of reading during the upper primary and secondary school years is necessary to ensure that all students continue to make progress throughout their education.

Considerable advancements have occurred in the last 30 years in understanding what the reading process is and what it means for a child to transition from novice to proficient by the middle years of primary school. Three international inquiries in the past 20 years have helped inform this understanding: the US National Reading Panel (2000), the Australian National Inquiry into the Teaching of Reading (Rowe, 2005), and the UK Independent Review of the Teaching of Early Reading (Rose, 2006). All three have emphasised the 
importance of teachers being highly knowledgeable about the linguistic constructs that underpin the English writing system ${ }^{2}$ and teaching beginning readers in ways that are explicit, systematic, and evidence-based.

It is important to regularly screen the progress of all students using reliable curriculum-based measures of achievement in reading to identify whether classroom teaching is adequately supporting all students to become skilled readers. In the early years of primary school, universal screening should specifically focus on decoding and language comprehension skills. If universal screens indicate particular students are underperforming on measures of reading, it is then important to undertake further assessments using valid and reliable measures that can detect particular difficulties at the subcomponent level, indicating whether any of the "big five" (phonemic awareness, phonics, fluency, vocabulary, comprehension) need support at a higher instructional tier (Graham, White, Tancredi, Snow, \& Cologon, 2020). Regular universal screening through curriculum-based measurement and high-quality measures of subcomponent skills enable timely identification of individuals requiring appropriately targeted intervention at a higher tier of classroom support, as enacted through the Response to Intervention (RTI; Fuchs \& Fuchs, 2006) and Multi-Tiered Systems of Support (MTSS; Hall, 2018) models.

Acting on data from well-validated assessment tools able to detect difficulties at the subcomponent level to monitor student progress and identify those needing support (Graham et al., 2020) reduces the likelihood of internalising and externalising mental health problems, both of which have high comorbidity with reading difficulties and require access to a range of expensive specialist services that are not always available (Snow, 2016). This policy is premised on the principle that the overwhelming majority $(95 \%)$ of children can and should be proficient readers by mid-primary school (Hempenstall, 2013) and that all students should be able to access effective support and intervention on an equitable basis (Chard, 2013).

\section{Purpose}

The purpose of this policy is to enable schools to provide high-quality evidencebased reading instruction and support to benefit every student. The policy is designed to assist schools in developing and implementing a consistent wholeschool approach that ensures all children receive optimal instruction using practices and programs that are supported by scientific evidence in lieu of those that have been found to be ineffective or for which there is insufficient supporting evidence. It also supports schools in using data to ensure that their resources are deployed on the basis of need to provide evidence-based and appropriately targeted interventions on an equitable and timely basis.

\section{Scope}

This policy applies to current and future classroom and specialist teachers, allied health professionals, school leaders, and parents of the students at [INSERT name of school]. A whole school approach to reading instruction and support is 
overseen by school leadership in partnership with parents and allied health professionals, such as school psychologists and speech-language pathologists.

\section{Policy statement}

School Management adopts a science of reading theoretical framework in which a clear emphasis is placed on the cognitive foundations of learning to read (Tunmer \& Hoover, 2019). This model is derived from the Simple View of Reading (Gough \& Tunmer, 1986) and emphasises the cognitive, linguistic, and background knowledge dimensions of early reading mastery. In particular, it recognises two complementary skill sets: word recognition and language comprehension (and a range of subsidiary skills under each), the teaching of which require high levels of teacher knowledge and explicit classroom instruction.

School Management also adopts a Multi-Tiered System of Supports (MTSS; Hall, 2018) model in which the evidence-based practices used for teaching reading to all students (Tier 1) are complemented by more intensive instruction to small groups of students performing somewhat below benchmarks (Tier 2) or to individuals performing well below benchmarks (Tier 3). Access to higher tiers of support is provided to students on the basis of school-wide screening, and student progress in Tiers 2 and 3 is routinely monitored. Interventions provided are those that are supported by best available evidence. In a recent longitudinal study in seven Australian primary schools, the evidence behind the various intervention programs and practices delivered was assessed. Only one of the programs used in these seven schools - MiniLIT - is supported by empirical evidence. The remaining programs and practices - Words Their Way, Guided Reading, Leveled Literacy Intervention, and Reading Eggs - are either supported by limited non-peer-reviewed evidence or no evidence. None had the requisite focus on phonics instruction to address the phonemic decoding weaknesses apparent in the participant sample (Graham et al., 2020).

Our school endeavours to employ capable teachers who are knowledgeable and skilled with respect to the linguistic basis of effective reading instruction and ongoing support. We commit to maintaining and strengthening teachers' skills within a culture of continuous improvement. We commit to supporting the reading progress of every student (Chard, 2013) regardless of age or disability.

[INSERT name of school] ensures that teachers have access to quality professional development that promotes the science of reading and discourages approaches for which the evidence base is weak or lacking (Moats, 2020; Snow, 2016).

[INSERT name of school] implements with fidelity teaching approaches, programs, and interventions that place a clear emphasis on the cognitive foundations of learning to read (Tunmer \& Hoover, 2019) and provides access to effective interventions according to student need. This model is derived from the Simple View of Reading (Gough \& Tunmer, 1986), emphasising the cognitive, linguistic, and background knowledge dimensions of early reading mastery. In particular, it recognises two complementary skill sets: word recognition and language comprehension, the acquisition of which require high levels of teacher knowledge and explicit classroom instruction. 
[INSERT name of school] consistently applies teaching approaches that promote systematic attention to phonemic awareness; knowledge of the alphabetic principle and its role in supporting children to decode through words; vocabulary, background knowledge, and comprehension skills. In the early stages, we employ decodable texts to promote practice and automaticity in phoneme-grapheme correspondences that have been explicitly taught. We routinely screen students for adequate progress in these areas, using wellvalidated, fit-for-purpose tools capable of assessing performance at the subcomponent level and on which staff have received training. We then provide more intensive, evidence-based interventions on the basis of these data for those students performing below benchmarks.

[INSERT name of school] does not support the use of instruction or intervention approaches that have poor alignment with the science of reading, most notably: commencing reading instruction by teaching large numbers of decontextualized "sight words" to be learnt by rote; using predictable, levelled texts in the early stages of reading; using the Three-Cueing (or Multi-Cueing) method; encouraging children to arrive at an unknown word by using context and picture cues; providing blocks of class time for silent reading; and/or using tools such as Running Records (Clay, 2002) to monitor progress.

\section{Teachers}

Teachers at [INSERT name of school] are recruited for their current level of knowledge of the science of reading and/or their willingness to be upskilled in this through in-house and other targeted forms of professional development.

Teachers at [INSERT name of school] understand the different types of phonics instruction (Wheldall et al., 2017) and their relative merits as early reading instruction approaches (Castles et al., 2018).

Teachers at [INSERT name of school] consistently adhere to pedagogical approaches informed by the science of reading at all classroom and intervention levels, in order to promote consistency of instructional and progress monitoring approaches and maximal opportunities for mastery, particularly in the case of students who struggle with reading (decoding and/or comprehension).

Teachers at [INSERT name of school] actively engage as part of a community of practice within the school to maintain and extend their knowledge of the science of reading and support peers to do the same.

Teachers at [INSERT name of school] provide evidence-based advice and resources to parents about how to support children at all stages of the reading process and provide guidance and support to parents who have questions about resources they locate through their own research.

\section{Parents}

Parents of children attending [INSERT name of school] are encouraged to be involved in early and ongoing reading instruction and will be provided with 
evidence-based printed materials, as well as opportunities to attend information sessions about the teaching of reading and approaches employed at [INSERT name of school].

Parents of children attending [INSERT name of school] are encouraged to focus on letters, letter sounds, and the decoding of words, along with vocabulary and inferencing skills when reading and playing with their child in the early years of primary school.

\section{Rating of evidence base}

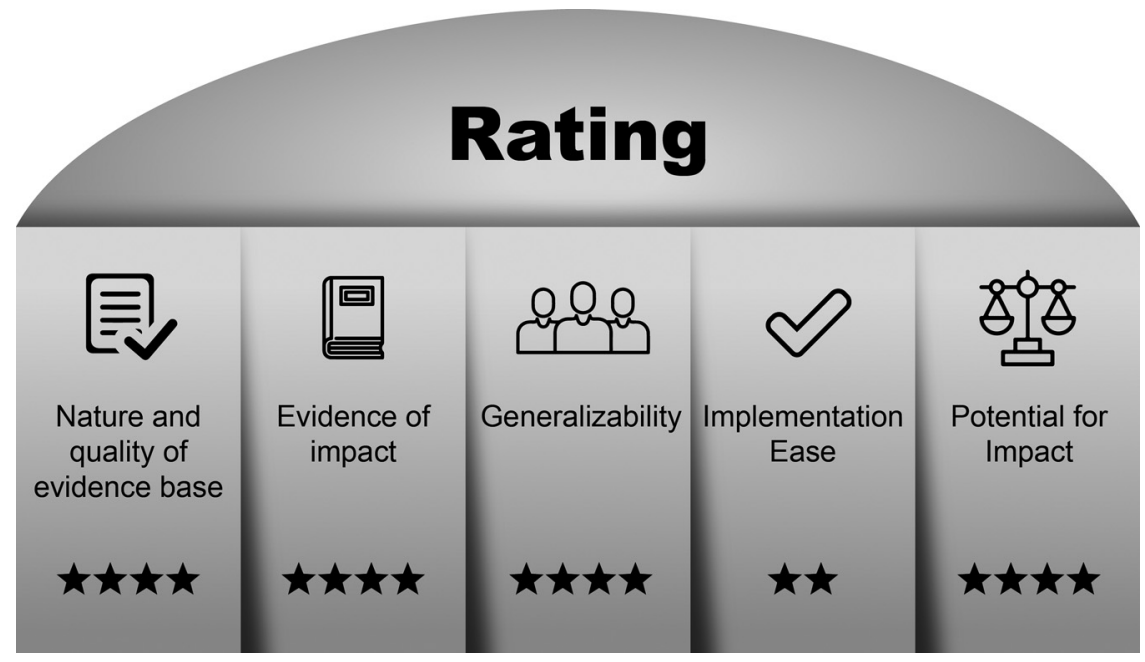

Figure 16.1. Applying the Science of Learning in the Classroom Rating of Evidence.

Author Note. The evidence itself that underpins this policy is strong. The translation of the existing body of evidence into teacher pre-service education and hence classroom practice has been weak. Many schools have a high degree of autonomy with respect to the way(s) in which they teach reading. Schools in which approaches outlined here have been systematically and sustainably adopted have demonstrated significant improvements in reading performance. Impact is, however, easily reduced by changes in key personnel within a school. The science of reading can be applied to schools regardless of the socioeconomic profile of the families in its community. There is some evidence, in fact, to suggest a disproportionate benefit for schools in low-socioeconomic status (SES) areas (Meyer, 1984) and/or those serving children from low-SES backgrounds (Stuart, 1999). Implementing this policy requires a clear whole-school vision for the teaching of reading, as well as strong and knowledgeable leadership who demonstrate a willingness to "stay the course" on a significant level of change over at least a three- to five-year period. It also requires a willingness by staff to discard familiar, though less impactful practices. The potential gains in student performance and behaviour associated with the adoption of this policy are substantial. However, this is challenging, for reasons noted above, with respect to the degree of knowledge and practice change required of staff and the professional development resources these demand. 


\author{
Authorship \\ Professor Pamela Snow, La Trobe University \\ Dr Kate de Bruin, Monash University \\ Professor Linda Graham, Queensland University of Technology \\ [INSERT RELEVANT STAFF MEMBERS]
}

\title{
Related policy and documents \\ [INSERT RELEVANT POLICY AND DOCUMENTS]
}

\section{Date of ratification}

This policy was ratified on the [INSERT DATE].

\section{Date of review}

This policy will be reviewed by [INSERT DATE].

\section{Notes}

1 Because the term "literacy" is sometimes applied to skills other than reading, writing, and spelling, in this chapter, we will refer to reading skills to explicitly connote the decoding and comprehension skills under consideration.

2 These include but are not limited to: the fact that English has a semi-transparent orthography; the fact that English is a morpho-phonemic language in which speech sounds (phonemes) are represented by letters and letter combinations (graphemes); and the fact that morphemes (small units of meaning within words) encode constructs such as plurality, negation, and tense. In English, we have 26 alphabet letters with which to represent 44 speech sounds, and we do this by using graphemes to represent those speech sounds which do not have a directly corresponding letter (e.g., the sound /g/ in "sheep" is represented by the grapheme "sh"). These and many related important concepts are covered by Moats (2000).

\section{References}

Castles, A., Rastle, K., \& Nation, K. (2018). Ending the reading wars: Reading acquisition from novice to expert. Psychological Science in the Public Interest, 19, 5-51.

Chard, D. J. (2013). Systems impact: Issues and trends in improving school outcomes for all learners through multitier instructional models. Intervention in School and Clinic, 48(4), 198-202.

Clay, M. M. (2002). An observation survey of early literacy achievement (2nd edition). Auckland: Heinemann.

Fuchs, D., \& Fuchs, L. S. (2006). Introduction to response to intervention: What, why, and how valid is it? Reading Research Quarterly, 41(1), 93-99.

Gough, P. \& Tunmer, W. (1986). Decoding, reading, and reading disability. Remedial and Special Education, 7, 6-10. 
Graham, L. J., White, S. L., Tancredi, H. A., Snow, P. C., \& Cologon, K. (2020). A longitudinal analysis of the alignment between children's early word-level reading trajectories, teachers' reported concerns and supports provided. Reading and Writing, 33, 1895-1923.

Hall, S. D. (2018). 10 success factors for literacy intervention: Getting results with MTSS in elementary schools. ASCD.

Hempenstall, K. (2013). What is the place for national assessment in the prevention and resolution of reading difficulties? Australian Journal of Learning Difficulties, $18,105-121$.

Meyer, L. A. (1984). Long-term academic effects of the direct instruction project follow through. The Elementary School Journal, 84(4), 380-394.

Moats, L. (2020). Speech to print: Language essentials for teachers (3rd ed.). Paul H. Brookes Publishing.

National Reading Panel (US), National Institute of Child Health, Human Development (US), National Reading Excellence Initiative, National Institute for Literacy (US), United States. Public Health Service, \& United States Department of Health. (2000). Report of the National Reading Panel: Teaching children to read: An evidence-based assessment of the scientific research literature on reading and its implications for reading instruction: Reports of the subgroups. National Institute of Child Health and Human Development, National Institutes of Health. https://www.nichd. nih.gov/sites/default/files/publications/pubs/nrp/Documents/report.pdf

Organisation for Economic Cooperation and Development [OECD]. (2019). Programme for International Student Assessment (PISA) results from PISA 2018. https://www. oecd.org/pisa/publications/

Rose, J. (2006) Independent review of the teaching of early reading. https://dera.ioe.ac. uk/5551/2/report.pdf

Rowe, K. (2005). National inquiry into the teaching of literacy. ACER. https://research. acer.edu.au/tll_misc/5/

Snow, P. (2016). Elizabeth Usher Memorial Lecture: Language is literacy is language. Positioning Speech Language Pathology in education policy, practice, paradigms, and polemics. International Journal of Speech Language Pathology, 18, 216-228.

Stuart, M. (1999). Getting ready for reading: Early phoneme awareness and phonics teaching improves reading and spelling in inner-city second language learners. British Journal of Educational Psychology, 69(4), 587-605.

Tunmer, W., \& Hoover, W. (2019). The cognitive foundations of learning to read: A framework for preventing and remediating reading difficulties. Australian Journal of Learning Difficulties, 24, 75-93.

Wheldall, K., Snow, P., \& Graham. L. (2017). Explainer: What does the term "synthetic phonics" really mean? LDA Bulletin, 49, 6-7. 